\title{
Rubpy Dye-Doped Silica Nanoparticles as Signal Reporter in a Dot Fluorescence Immunoassay Strip
}

\author{
Nualrahong Thepwiwatjit, ${ }^{1}$ Aree Thattiyaphong, ${ }^{2}$ Pichet Limsuwan, ${ }^{3}$ \\ Kooranee Tuitemwong, ${ }^{4}$ and Pravate Tuitemwong ${ }^{5}$ \\ ${ }^{1}$ Program in Bioscience, Faculty of Science, King Mongkut's University of Technology Thonburi, Bangkok 10140, Thailand \\ ${ }^{2}$ Department of Medical Sciences, National Institute of Health, Tiwanon Road, Nonthaburi 11000, Thailand \\ ${ }^{3}$ Department of Physics, Faculty of Science, King Mongkut's University of Technology Thonburi, Bangkok 10140, Thailand \\ ${ }^{4}$ Department of Microbiology, Faculty of Science, Kasetsart University, Bangkok 10900, Thailand \\ ${ }^{5}$ Food Safety Center, Institute of Scientific and Technological Research and Services, King Mongkut's University of Technology Thonburi, \\ Bangkok 10140, Thailand
}

Correspondence should be addressed to Pravate Tuitemwong; ptt59@hotmail.com

Received 27 November 2013; Revised 3 January 2014; Accepted 4 January 2014; Published 18 February 2014

Academic Editor: William W. Yu

Copyright (C) 2014 Nualrahong Thepwiwatjit et al. This is an open access article distributed under the Creative Commons Attribution License, which permits unrestricted use, distribution, and reproduction in any medium, provided the original work is properly cited.

\begin{abstract}
This paper describes an application of Rubpy dye-doped silica nanoparticles (RSNPs) as signal reporter in a dot fluorescence immunoassay strip for rapid screening of Vibrio cholera O1 (VCO1). These nanoparticles have a spherical shape with an average diameter of $45 \mathrm{~nm}$. They appear luminescent orange when excited with a $312 \mathrm{~nm}$ UV lamp. Based on the sandwich immunoassay principle, a test strip was made of a nitrocellulose membrane dotted with monoclonal antibodies against VCO1 as analyte capture molecules. After introducing a test sample, followed by polyclonal rabbit anti-VCO1 antibody conjugated RSNPs as detection reporters and one washing step, the presence or absence of the target bacteria could be identified under UV light by naked eyes. A positive sample would signal a bright orange dot on the strip. The proposed assay had a detection limit of $4.3 \times 10^{3} \mathrm{cfu} / \mathrm{mL}$ and was successfully applied as a rapid screening test for VCO1 in food samples with high sensitivity, specificity, and accuracy.
\end{abstract}

\section{Introduction}

Nowadays, immuno-based flow strip assay is one of most common devices for rapid detection of a number of analytes and has been used in various fields. Most tests work by capturing analytes on a membrane followed by attaching detection molecules to them which allow detection by naked eye [1]. The most commonly used detection particles in commercial are colloidal gold. However, some researchers claimed that this conventional marker could not detect some targets at very low concentrations. This limitation happens to be a serious problem when high sensitivity is needed, such as the early diagnosis of some vital diseases [2,3]. Accordingly, there is a need to explore new reporters which can overcome these margins to keep up with new challenges in detection at very low concentrations of some targets. It was suggested that fluorescent nanoparticles are promising alternative because of their greater sensitivity.

During the past decade, fluorescent dye-doped silica nanoparticles have been developed and used in diverse biological applications [4-8] including the detection of undesired bacteria or toxin in clinical fluids and environmental samples as well as food and drinking water [9-13]. These nanomaterials have attracted widespread interest due to their unique properties. First, they provide high fluorescence intensity caused by thousands of dye molecules captured inside a silica matrix $[4,14,15]$. Second, the silica shell protects the dye from surrounding environment resulting in a more superior photostability than single dye itself $[5,16,17]$. Third, the silica surface can be easily modified with different types of functional groups such as hydroxyl, amino, and carboxyl groups which can be used to incorporate with a 
variety of biomolecules as needed $[15,18]$. Moreover, because of the high density of silica, they are easy to separate by centrifugation during particle synthesis, surface modification, and other solution treatment processes [15]. To conclude, these fluorescent silica nanoparticles are physically stable, chemically inert, versatile, biocompatible, and suitable for different physiological conditions [19].

However, using these nanomaterials as detection particles requires specific equipment to detect or monitor their fluorescence signals such as spectrofluorometer $[9,13]$, fluorescence microscope $[9,17,20]$, confocal microscope $[12,21]$ and flow cytometer [22]. This necessity might be the reason that there is no study reporting an employment of these materials in a strip assay for a point-of-care or field test although they have been of interest as a fascinating fluorescent probe and attracted widespread application in biology and medicine for years.

In this research, we aimed to study the potential use of these fluorescent dye-doped silica nanoparticles as signal reporters in an immuno-based strip assay for visual detection without using complicated read-out instrument. The Rubpy dye was chosen as fluorescence dye encapsulated inside the silica matrix because it emits bright orange fluorescence which is attractive to the naked eye and thus would be suitable for further application. Firstly, a portable light source required to properly excite the Rubpy dye-doped silica nanoparticles (RSNPs) was developed and investigated. After that, a dot fluorescence immunoassay strip was developed using these nanoparticles to detect the presence or absence of a target analyte in a sample. This solid-phase format [23] was chosen as its components matched the accessibility of our laboratory.

For the development of any immunoassay test, antibodies are the key components. In this work, Vibrio cholerae O1 was chosen as model analyte by reason of the availability of the compatible antibodies used in the experiments. V. cholerae is a causative agent of cholera which is a food and waterborne gastroenteric infection. It is one of the most significant threats to public health in the developing countries [24] and any method which can rapidly screen and detect this bacterium is always needed.

\section{Methodology}

2.1. Materials. Tetraethyl orthosilicate (TEOS), tris(2,2'bipyridyl)dichlororuthenium(II) hexahydrate (Rubpy dye), ammonium hydroxide $\left(\mathrm{NH}_{4} \mathrm{OH}\right)$, trimethoxysilyl-propyldiethylenetriamine (DETA), succinic anhydride, and bovine serum albumin (BSA) were purchased from Sigma-Aldrich. Z-morpholinoethanesulfonic acid (MES), 1-ethyl-3-(3-dimethylaminopropyl) carbodiimide hydrochloride (EDC), and $\mathrm{N}$-hydroxysuccinimide (NHS) were purchased from Merck. Cyclohexane, n-hexanol, N,N-dimethylformamide (DMF), Triton X-100, and all other chemicals of analytical reagent grade were obtained from either Fisher Scientific or a local company. Nitrocellulose membrane sheet was from Whatman. Polyclonal rabbit anti-Vibrio cholerae $\mathrm{O} 1$ antibody, and monoclonal antibody specific to Vibrio cholerae $\mathrm{Ol}$ were obtained from the National Institute of Health, Department of Medical Science, Thailand.

2.2. Synthesis of Rubpy Dye-Doped Silica Nanoparticles. Rubpy dye-doped silica nanoparticles (RSNPs) were synthesized using a water-in-oil microemulsion technique as described in [20]. Briefly, cyclohexane, aqueous Rubpy dye solution, Triton X-100, and n-hexanol were used as oil phase, water phase, surfactant, and cosurfactant, respectively. The mixtures were homogenized using a magnetic stirrer in order to form water-in-oil microemulsion. After that, TEOS was added as silica precursor and $\mathrm{NH}_{4} \mathrm{OH}$ was added to initiate polymerization. After vigorous stirring for $24 \mathrm{~h}$, acetone was added and RSNPs were precipitated. The particles were collected and washed with $95 \%$ ethanol (3 times) and deionized water ( 2 times). The particles were air-dried and kept in amber bottles until use.

\subsection{Characterization of Rubpy Dye-Doped Silica Nanoparti-} cles. To indicate the size of the synthesized particles, a sample of nanoparticles dispersed in $95 \%$ ethanol $(1 \mathrm{mg} / \mathrm{mL})$ was imaged using a transmission electron microscope (TEM) (TECNAI 20 TWIN, USA). Diameters of about 100 particles on the pictures were randomly measured via program ImageJ. Mean and standard deviation (SD) were calculated.

For absorption spectrum, a sample of RSNPs dispersed in deionized water $(1 \mathrm{mg} / \mathrm{mL})$ was analyzed with a UV/Visible spectrophotometer (HACH DR/4000U). Using wavelength scan mode, the sample was scanned from $200 \mathrm{~nm}$ to $800 \mathrm{~nm}$ in $5 \mathrm{~nm}$ increments. Data were plotted with the absorbance on vertical axis versus the wavelength on horizontal axis.

2.4. Surface Modification and Antibody Conjugation. The RSNPs were surface modified with carboxyl group using the method described by Zhao et al. [9] with some modification. First, the RSNPs were reacted with $1 \%$ DETA in $1 \mathrm{mM}$ acetic acid for $30 \mathrm{~min}$ at room temperature with continuous stirring. Then they were separated and washed with deionized water several times. The particles were mixed with $10 \%$ succinic anhydride in N,N-dimethylformamide and stirred under $\mathrm{N}_{2}$ gas for 6 hours. The carboxyl-functionalized silica nanoparticles (CNPs) were collected and washed several times. To conjugate with polyclonal rabbit anti-VCO1 antibody (PAb), CNPs were mixed with $1 \%$ EDC and $1 \%$ NHS in 0.1 M MES buffer ( $\mathrm{pH}$ 5.5) for $30 \mathrm{~min}$. Then they were mixed with $\mathrm{PAb}$ in $0.01 \mathrm{M}$ PBS ( $\mathrm{pH} 7.4$ ) for $4 \mathrm{~h}$ at room temperature with gentle shaking. After that, they were reacted with $1 \%$ BSA blocking agent for $30 \mathrm{~min}$. The antibody-conjugated RSNPs were washed and kept at $4^{\circ} \mathrm{C}$ until use.

A scanning electron microscope (SEM) (HITACHI SEM S-2500, Japan) was used to image a sample of the nanoparticles incubated with cell suspension of VCO1 to confirm the achievement of antibody conjugation step.

2.5. Preparation of a Dot Fluorescence Immunoassay Strip. A nitrocellulose membrane sheet was cut into strips $(0.5 \mathrm{~cm}$ $\times 2.0 \mathrm{~cm}$ ). Approximately $5 \mathrm{~mm}$ above the end of the strip, $1 \mu \mathrm{L}$ of monoclonal antibodies against VCO1 $(1 \mathrm{mg} / \mathrm{mL})$ was 
dotted as capture molecules. The strips were dried in a desiccator at room temperature over-night. After that, the strips were immersed in a blocking buffer containing $2 \%$ skim milk. Excess solution was blotted off. The membranes were dried and kept in a desiccator until use.

2.6. Assay Procedure. The test procedure for detecting the target bacteria was as follows. First, the strip was immersed in approximately $200 \mu \mathrm{L}$ of sample for about $1 \mathrm{~min}$. At this point, the target bacteria, (if present) would bind to the immobilized antibody at the test zone. Then the strip was removed, rinsed once with $0.01 \mathrm{M}$ PBS ( $\mathrm{pH}$ 7.4) to remove unbound bacteria, and dipped in an amount of reporter solution for 1-2 min. The RSNPs were then bound to the target bacteria previously immobilized at the capture zone. Finally, the strip was washed in PBS with $1 \%$ Tween-20 for $10-15$ min with continuous shaking. Excess solution was blotted off and the test result was examined under a UV lamp $(312 \mathrm{~nm})$. A positive result was indicated by a fluorescent orange dot on the membrane, whereas a negative result showed no signal on the strip.

\section{Results and Discussion}

3.1. Synthesis and Characterization of Fluorescent Dye-Doped Silica Nanoparticles. The Rubpy dye-doped silica nanoparticles (RSNPs) were prepared using a water-in-oil microemulsion technique as described in [20]. Inside the water dispersing phase, the silica precursor (TEOS) undergoes hydrolysis and polycondensation reactions and finally forms the monodisperse spherical silica particles [24]. Simultaneously, the fluorescent Rubpy dye molecules dissolved within the water droplets were encapsulated in the silica network through this process. By adding acetone, RSNPs were precipitated. After centrifugation, washing, and drying, an amount of fine reddish brown powder of RSNPs was obtained. Under a transmission electron microscope (TEM), it was found that the RSNPs were spherical in shape with an average size of $45 \mathrm{~nm}$ and well dispersed in the solution (Figure 1).

Since one objective of our study was to develop a simple tool for a point-of-care or field test using these RSNPs as signal reporter, a portable light source is essentially required to properly excite the RSNPs for visual detection without using complicated read-out instrument. From previous study [20], it was found that the RSNPs exhibited an emission at $598 \mathrm{~nm}$ when excited at $453 \mathrm{~nm}$. A lamp with this optimal excitation wavelength is rather difficult to find in the market, unlike a UV lamp for bioscience application which is more available with selectable wavelengths. Thus, a UV lamp was of interest for this study.

To determine wavelengths that the RSNPs can absorb, especially in the range of UV light, an absorption spectrum of the sample was investigated using a UV/Visible spectrophotometer. Figure 2 shows an absorption spectrum from $200 \mathrm{~nm}$ to $800 \mathrm{~nm}$ of the RSNPs in aqueous solution. Despite the highest absorbance at approximately $290 \mathrm{~nm}$, it can be seen that the absorbance at $312 \mathrm{~nm}$ is comparable to the absorbance at $450 \mathrm{~nm}$ which is in the range of the optimal excitation wavelength for RSNPs. From these findings, it was

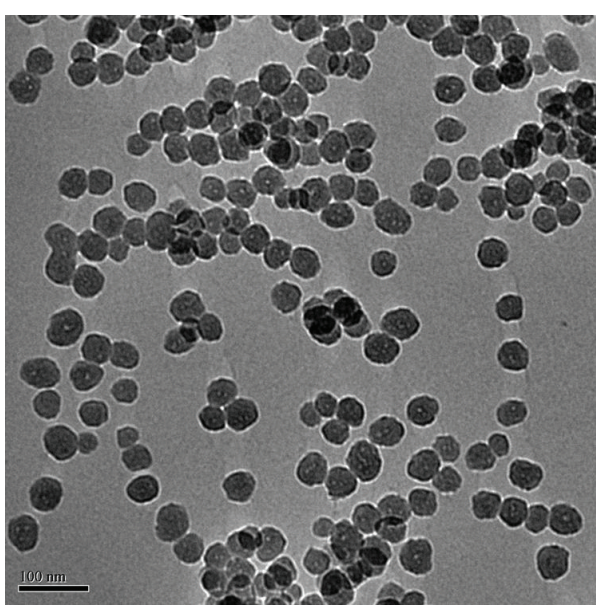

Figure 1: A transmission electron microscope image at 25,000x magnification showing well-dispersed spherical shape of Rubpy dyedoped silica nanoparticles.

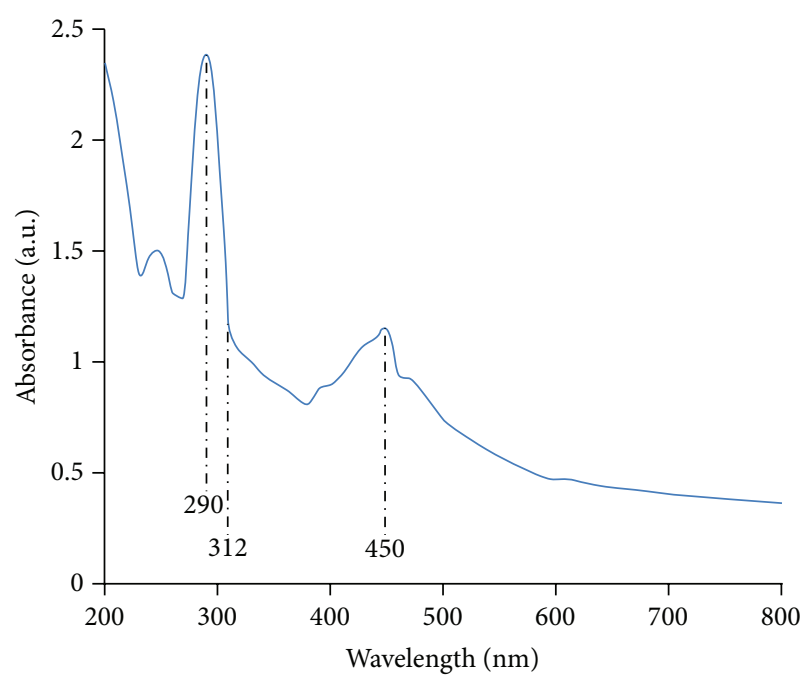

FIGURE 2: Absorption spectrum of the Rubpy dye-doped silica nanoparticles.

assumed that the RSNPs could be excited under UV light $(312 \mathrm{~nm})$ and yield similar emission. This wavelength is also an available UV lamp in most bioscience laboratories.

This assumption was proved with evidence that the RSNPs in aqueous solution appeared luminescent orange when excited with a $312 \mathrm{~nm}$ UV lamp (Figure 3(b)). Therefore, this UV lamp would be used as excitation light source for the developed test strip using RSNPs as reporter probe in further experiment.

3.2. Surface Modification and Antibody Conjugation. Before conjugating with antibody specific for the target microorganism, the surfaces of RSNPs were firstly chemically modified. In this study, the carboxyl groups were formed onto the nanoparticle surfaces. After that, the particles were conjugated with polyclonal antibody against VCO1. The achievement of antibody conjugation step was confirmed by taking a 


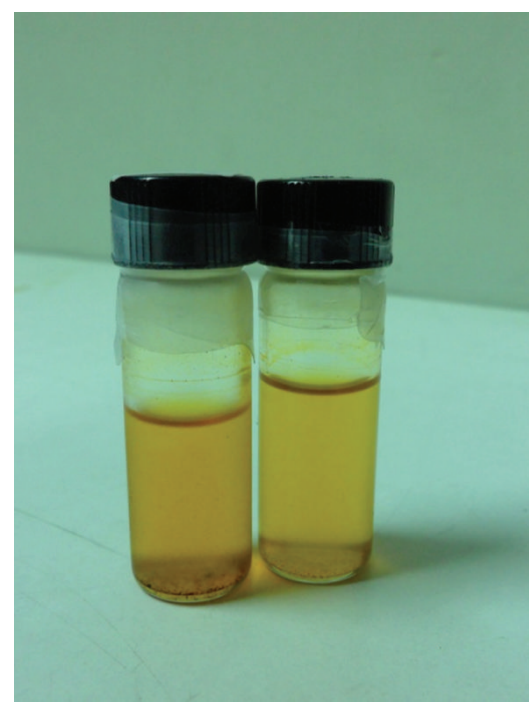

(a)

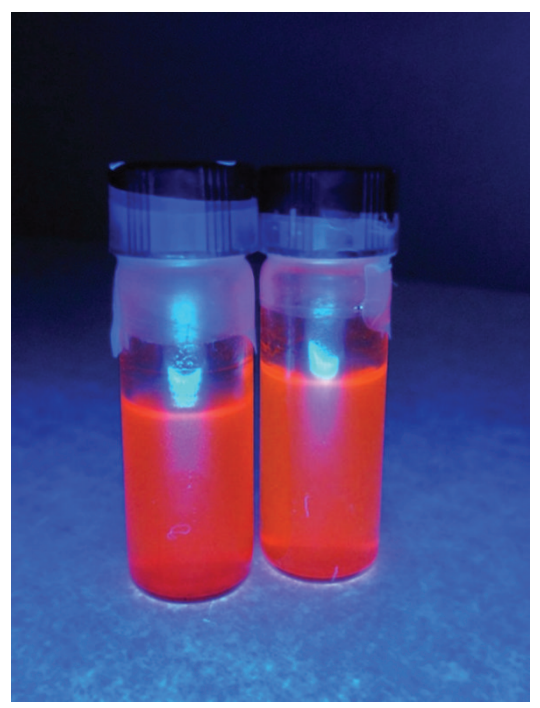

(b)

FIGURE 3: Rubpy dye-doped silica nanoparticles in aqueous solution (a) under daylight and (b) under UV light (312 nm).

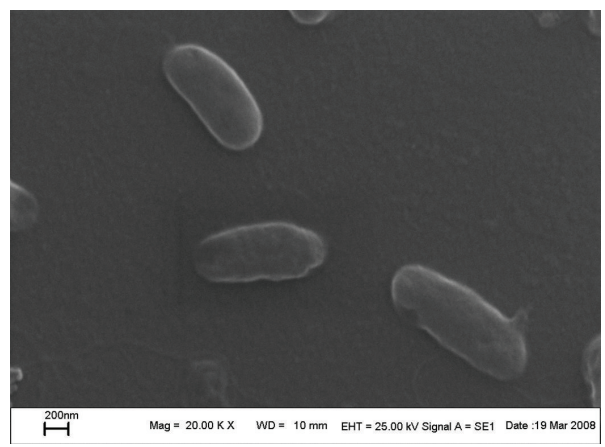

(a)

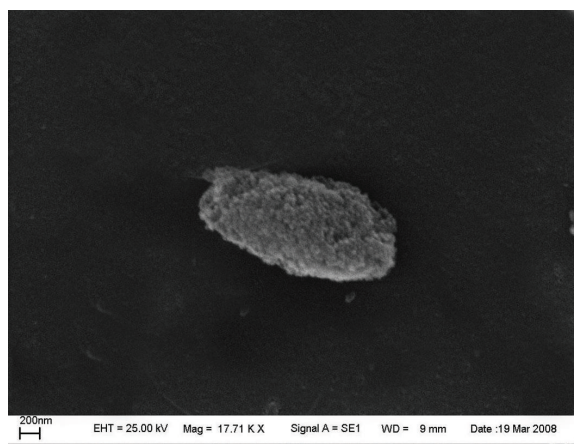

(b)

FIGURE 4: A scanning electron microscope image (a) bacteria incubated with RSNPs without antibody and (b) bacteria incubated with antibody-conjugated RSNPs.

scanning electron microscope (SEM) of a sample of the target bacteria incubated with antibody-conjugated RSNPs. The results showed that the antibodies were successfully attached onto the nanoparticles as there were a number of tiny spheres of RSNPs bound to the bacterium cell making it look like a breaded shrimp (Figure 4(b)). On the contrary, there was nothing coated on the cell when the bacteria were incubated with RSNPs without antibody (Figure 4(a)).

3.3. Dot Fluorescence Immunoassay Strip. For the development of the test assay, we cut a nitrocellulose membrane sheet into strips with a small right-corner cut on the top of each strip to indicate face-up side. Monoclonal antibody against VCO1 was dotted at approximately $5 \mathrm{~mm}$ above the end of the strip. After that, the strip was blocked with $2 \%$ skim milk to prevent nonspecific binding [25].

To determine the detection limit of the test strip, a series of bacteria VCO1 dilutions between $4.3 \times 10^{1} \mathrm{cfu} / \mathrm{mL}$ and $4.3 \times 10^{8} \mathrm{cfu} / \mathrm{mL}$ were tested. Blank alkaline peptone water $(\mathrm{APW})$ was used as a negative control $(0 \mathrm{cfu} / \mathrm{mL})$. The results

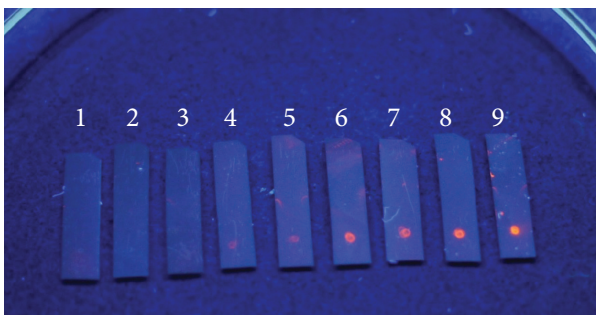

Figure 5: The detection of Vibrio cholera $\mathrm{O} 1$ by the developed dot fluorescence immunoassay strip. The strips were dipped in samples containing VCO1 in ranges (1) $0 \mathrm{cfu} / \mathrm{mL}$ (control), (2) $4.3 \times$ $10^{1} \mathrm{cfu} / \mathrm{mL},(3) 4.3 \times 10^{2} \mathrm{cfu} / \mathrm{mL}$, (4) $4.3 \times 10^{3} \mathrm{cfu} / \mathrm{mL}$, (5) $4.3 \times$ $10^{4} \mathrm{cfu} / \mathrm{mL},(6) 4.3 \times 10^{5} \mathrm{cfu} / \mathrm{mL}$, (7) $4.3 \times 10^{6} \mathrm{cfu} / \mathrm{mL}$, (8) $4.3 \times$ $10^{7} \mathrm{cfu} / \mathrm{mL}$, and (9) $4.3 \times 10^{8} \mathrm{cfu} / \mathrm{mL}$.

showed that an orange dot was found at the concentration of VCO1 as low as $4.3 \times 10^{3} \mathrm{cfu} / \mathrm{mL}$ (Figure 5). Therefore, the detection limit of this dot fluorescence immunoassay strip 


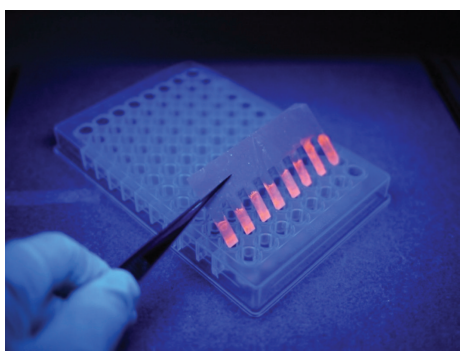

(a)

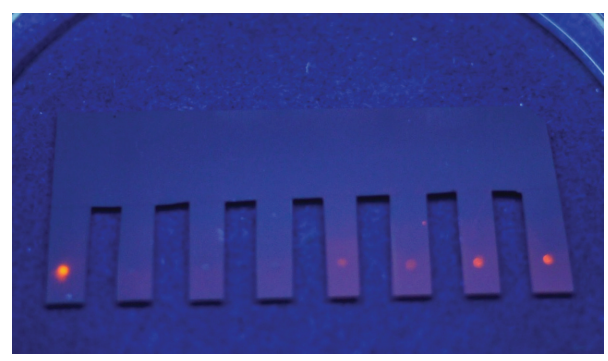

(b)

FIgURE 6: A dot fluorescence immunoassay dipstick comb for rapid screening of Vibrio cholera $\mathrm{O} 1$ in seven samples within one assay (a) during test and (b) test result.

TABLE 1: Comparison of dot fluorescence immunoassay strips to cultural method in the detection of Vibrio cholera $\mathrm{O} 1$ in food samples.

\begin{tabular}{lccc}
\hline & \multicolumn{2}{c}{ Cultural method } & \multirow{2}{*}{ Total } \\
& Positive & Negative & \\
\hline Dot fluorescence & & & \\
immunoassay strips & & & \\
$\quad$ Positive & 6 & 1 & 7 \\
$\quad$ Negative & 0 & 23 & 23 \\
\hline Total & 6 & 24 & $N=30$ \\
\hline
\end{tabular}

was $4.3 \times 10^{3} \mathrm{cfu} / \mathrm{mL}$. Through these test procedures, the result could be obtained within approximately $20 \mathrm{~min}$ after the sample had been introduced.

Several methods for $V$. cholerae detection that have been published recently show a wide range of detection limits, for example, 10-100 CFU via PCR-based method by Mehrabadi et al. [26], 10 CFU using a dipstick test by Chakraborty et al. [27], and $5 \times 10^{5} \mathrm{cfu} / \mathrm{mL}$ through an immunochromatographic strip test by Chaivisuthangkura et al. [28]. However, these limits could not be compared due to the different target analytes, detection reporters and antibody system used in each assay. To this point, we evaluated our findings that the detection time and detection limit of our developed strips were considered satisfactory.

To evaluate the performance of our developed strips for detecting VCO1, the strips were tested with 30 suspected VCO1 contamination food samples purchased from local markets in comparison to the standard cultural method for VCO1 (FDA-BAM). Sensitivity, specificity, false positive, false negative, and accuracy values of the developed test strip were calculated using two-by-two contingency table (Table 1).

It was found that this assay had sensitivity, specificity, false positive, and accuracy values of $100 \%, 95.83 \%, 4.17 \%$, and $96.67 \%$, respectively. There was no false negative result in this study. One false positive result might be due to the system detected bacteria cell either dead or alive via antibodyantigen reaction while the cultural method detected only active cell that could reproduce in culture media. Therefore, if the sample contained bacteria which were too weak to grow in culture media, the result from cultural method would be negative while the result from this tool would be positive.
To make this format able to test several samples at once, a dipstick comb was further developed (Figure 6). This comb was composed of 8 teeth that fit 8 wells on a microtiter plate. On the left tooth of the comb, an amount of goat anti-rabbit IgG was dotted as a control dot. When the strip was run, an orange dot would appear on this tooth to indicate that the RSNPs as detection particles were still valid. Moreover, it was found that antibody-conjugated RSNPs kept at $4^{\circ} \mathrm{C}$ up to 15 months still effectively performed in the test system.

\section{Conclusions}

A UV lamp ( $312 \mathrm{~nm}$ ) was found to be a proper light source with ease of use for reading signal from the Rubpy dyedoped silica nanoparticles. Accordingly, these fluorescent silica nanoparticles showed a potential application as signal reporters in a dot fluorescence immunoassay strip for rapid screening of VCO1 with a detection limit of $4.3 \times 10^{3} \mathrm{cfu} / \mathrm{mL}$. The developed method was successfully applied to discover VCO1 in food samples with high sensitivity, specificity, and accuracy within short analysis time (20 min). This assay offers a reliable method for the detection of VCO1 in a wide area such as food safety and clinical diagnosis. This principle could be applied in a form of a dipstick comb which could detect 7 samples in a microtiter plate in one assay. Lastly, the findings also encourage the use of RSNPs as signal reporters to improve detection limit of immunochromatographic test strips for various kinds of analytes in the future work.

\section{Conflict of Interests}

The authors declare that there is no conflict of interests regarding the publication of this paper.

\section{Acknowledgments}

This work was supported in part by National Research Council of Thailand. The authors thank the National Institute of Health, Department of Medical Science for the production of antibodies specific to Vibrio cholera O1. They also thank Dhonburi Rajabhat University for providing laboratory facility for this work. 


\section{References}

[1] http://www.rapid-diagnostics.org/technologies.htm.

[2] Y. Bai, C. Tian, X. Wei, Y. Wang, D. Wang, and X. Shi, "A sensitive lateral flow test strip based on silica nanoparticle/CdTe quantum dot composite reporter probes," RSC Advances, vol. 2, no. 5, pp. 1778-1781, 2012.

[3] E. M. Linares, L. T. Kubota, J. Michaelis, and S. Thalhammer, "Enhancement of the detection limit for lateral flow immunoassays: evaluation and comparison of bioconjugates," Journal of Immunological Methods, vol. 375, no. 1-2, pp. 264-270, 2012.

[4] S. Santra, K. Wang, R. Tapec, and W. Tan, "Development of novel dye-doped silica nanoparticles for biomarker application," Journal of Biomedical Optics, vol. 6, no. 2, pp. 160-166, 2001.

[5] S. Santra, P. Zhang, K. Wang, R. Tapec, and W. Tan, "Conjugation of biomolecules with luminophore-doped silica nanoparticles for photostable biomarkers," Analytical Chemistry, vol. 73, no. 20, pp. 4988-4993, 2001.

[6] W. Lian, S. A. Litherland, H. Badrane et al., "Ultrasensitive detection of biomolecules with fluorescent dye-doped nanoparticles," Analytical Biochemistry, vol. 334, no. 1, pp. 135-144, 2004.

[7] W. Yang, C. G. Zhang, H. Y. Qu, H. H. Yang, and J. G. Xu, "Novel fluorescent silica nanoparticle probe for ultrasensitive immunoassays," Analytica Chimica Acta, vol. 503, no. 2, pp. 163-169, 2004.

[8] L. M. Rossi, L. Shi, F. H. Quina, and Z. Rosenzweig, "Stöber synthesis of monodispersed luminescent silica nanoparticles for bioanalytical assays," Langmuir, vol. 21, no. 10, pp. 4277-4280, 2005.

[9] X. Zhao, L. R. Hilliard, S. J. Mechery et al., "A rapid bioassay for single bacterial cell quantitation using bioconjugated nanoparticles," Proceedings of the National Academy of Sciences of the United States of America, vol. 101, no. 42, pp. 15027-15032, 2004.

[10] X. Hun and Z. Zhang, "A novel sensitive staphylococcal enterotoxin $\mathrm{C} 1$ fluoroimmunoassay based on functionalized fluorescent core-shell nanoparticle labels," Food Chemistry, vol. 105, no. 4, pp. 1623-1629, 2007.

[11] X. Hun and Z. Zhang, "Functionalized fluorescent core-shell nanoparticles used as a fluorescent labels in fluoroimmunoassay for IL-6," Biosensors and Bioelectronics, vol. 22, no. 11, pp. 27432748, 2007.

[12] D. Qin, X. He, K. Wang, X. J. Zhao, W. Tan, and J. Chen, "Fluorescent nanoparticle-based indirect immunofluorescence microscopy for detection of Mycobacterium tuberculosis," Journal of Biomedicine and Biotechnology, vol. 2007, Article ID 89364, 2007.

[13] Z. Wang, T. Miu, H. Xu, N. Duan, X. Ding, and S. Li, "Sensitive immunoassay of Listeria monocytogenes with highly fluorescent bioconjugated silica nanoparticles probe," Journal of Microbiological Methods, vol. 83, no. 2, pp. 179-184, 2010.

[14] X. Zhao, R. P. Bagwe, and W. Tan, "Development of organic-dyedoped silica nanoparticles in a reverse microemulsion," Advanced Materials, vol. 16, no. 2, pp. 173-176, 2004.

[15] L. Wang, K. Wang, S. Santra et al., "Watching silica nanoparticles glow in the biological world," Analytical Chemistry, vol. 78, no. 3, pp. 646-654, 2006.

[16] R. Tapec, X. J. Zhao, and W. Tan, "Development of organic dyedoped silica nanoparticles for bioanalysis and biosensors," Journal of Nanoscience and Nanotechnology, vol. 2, no. 3-4, pp. 405409, 2002.
[17] W. Tansub, K. Tuitemwong, P. Limsuwan, S. Theparoonrat, and P. Tuitemwong, "Synthesis of antibodies-conjugated fluorescent dye-doped silica nanoparticles for a rapid single step detection of Campylobacter jejuni in live poultry," Journal of Nanomaterials, vol. 2012, Article ID 865186, 7 pages, 2012.

[18] L. Wang, W. Zhao, and W. Tan, "Bioconjugated silica nanoparticles: development and applications," Nano Research, vol. 1, no. 2, pp. 99-115, 2008.

[19] J. Yan, M. C. Estévez, J. E. Smith et al., "Dye-doped nanoparticles for bioanalysis," Nanotoday, vol. 2, no. 3, pp. 44-50, 2007.

[20] N. Thepwiwatjit, A. Thattiyaphong, P. Limsuwan, K. Tuitemwong, and P. Tuitemwong, "Antibody-conjugated Rubpy dyedoped silica nanoparticles as signal amplification for microscopic detection of Vibrio cholerae O1," Journal of Nanomaterials, vol. 2013, Article ID 274805, 7 pages, 2013.

[21] L. Wang, W. Zhao, M. B. O’Donoghue, and W. Tan, "Fluorescent nanoparticles for multiplexed bacteria monitoring," Bioconjugate Chemistry, vol. 18, no. 2, pp. 297-301, 2007.

[22] L. Wang, C. Yang, and W. Tan, "Dual-luminophore-doped silica nanoparticles for multiplexed signaling," Nano Letters, vol. 5, no. 1, pp. 37-43, 2005.

[23] http://www.rapid-diagnostics.org/tech-solid.htm.

[24] M. A. Jensen, S. M. Faruque, J. J. Mekalanos, and B. R. Levin, "Modeling the role of bacteriophage in the control of cholera outbreaks," Proceedings of the National Academy of Sciences of the United States of America, vol. 103, no. 12, pp. 4652-4657, 2006.

[25] R. Verheijen, "Immunological strip tests," in Analytical Biotechnology, T. G. M. Schalkhammer, Ed., pp. 134-166, Basel, 2002.

[26] J. F. Mehrabadi, P. Morsali, H. R. Nejad, and A. A. Imani Fooladi, "Detection of toxigenic Vibrio cholerae with new multiplex PCR," Journal of Infection and Public Health, no. 3, pp. 263-267, 2012.

[27] S. Chakraborty, M. Alam, H. M. Scobie, and D. A. Sack, "Adaptation of a simple dipstick test for detection of Vibrio cholerae $\mathrm{O} 1$ and $\mathrm{O} 139$ in environmental water," Frontiers in Microbio$\log y$, vol. 4, article 320, 2013.

[28] P. Chaivisuthangkura, C. Pengsuk, S. Longyant, and P. Sithigorngul, "Evaluation of monoclonal antibody based immunochromatographic strip test for direct detection of Vibrio cholerae O1 contamination in seafood samples," Journal of Microbiological Methods, vol. 95, no. 2, pp. 304-311, 2013. 

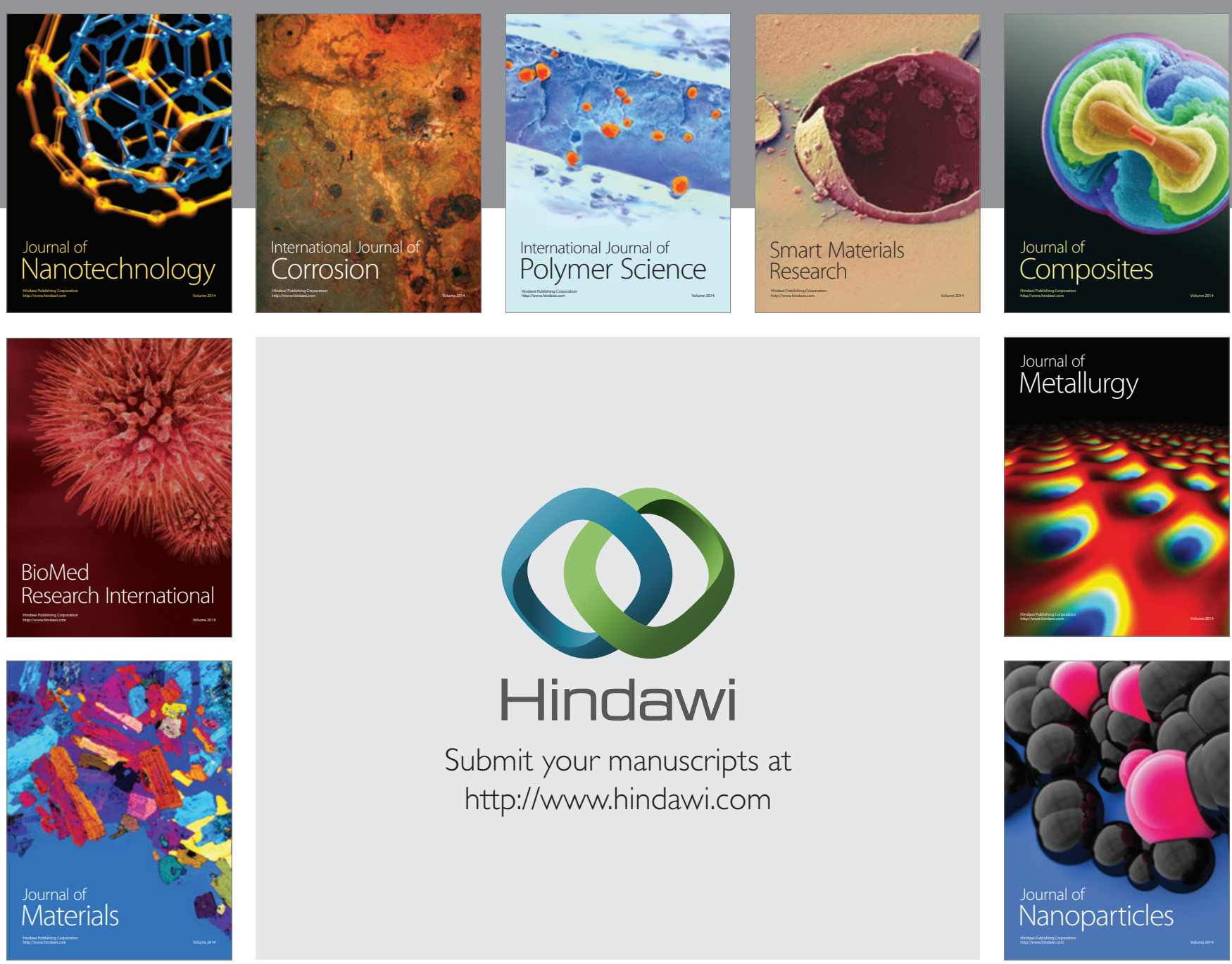

Submit your manuscripts at http://www.hindawi.com
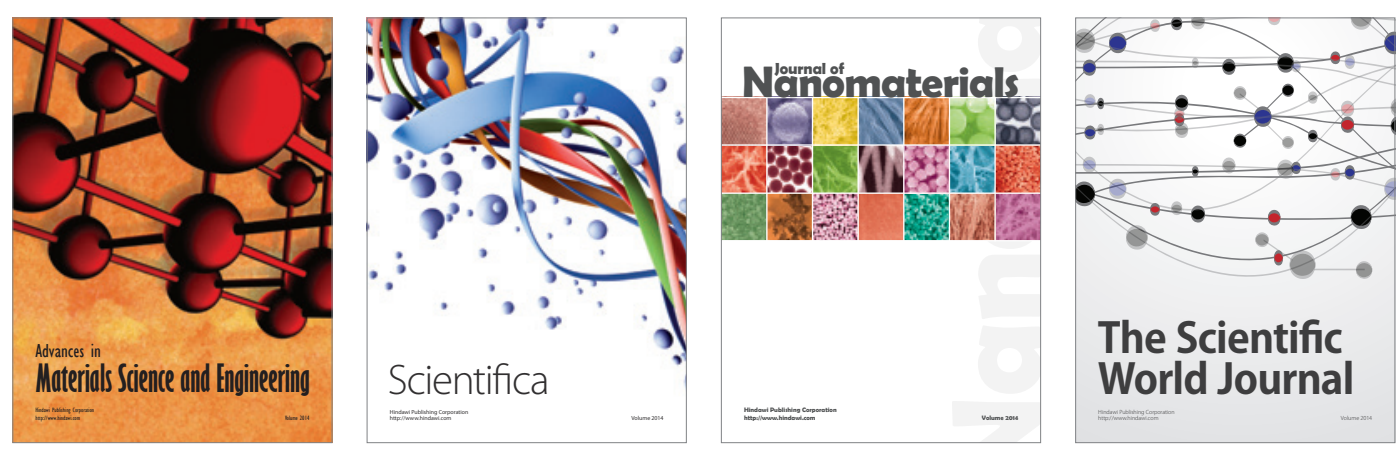

\section{The Scientific World Journal}
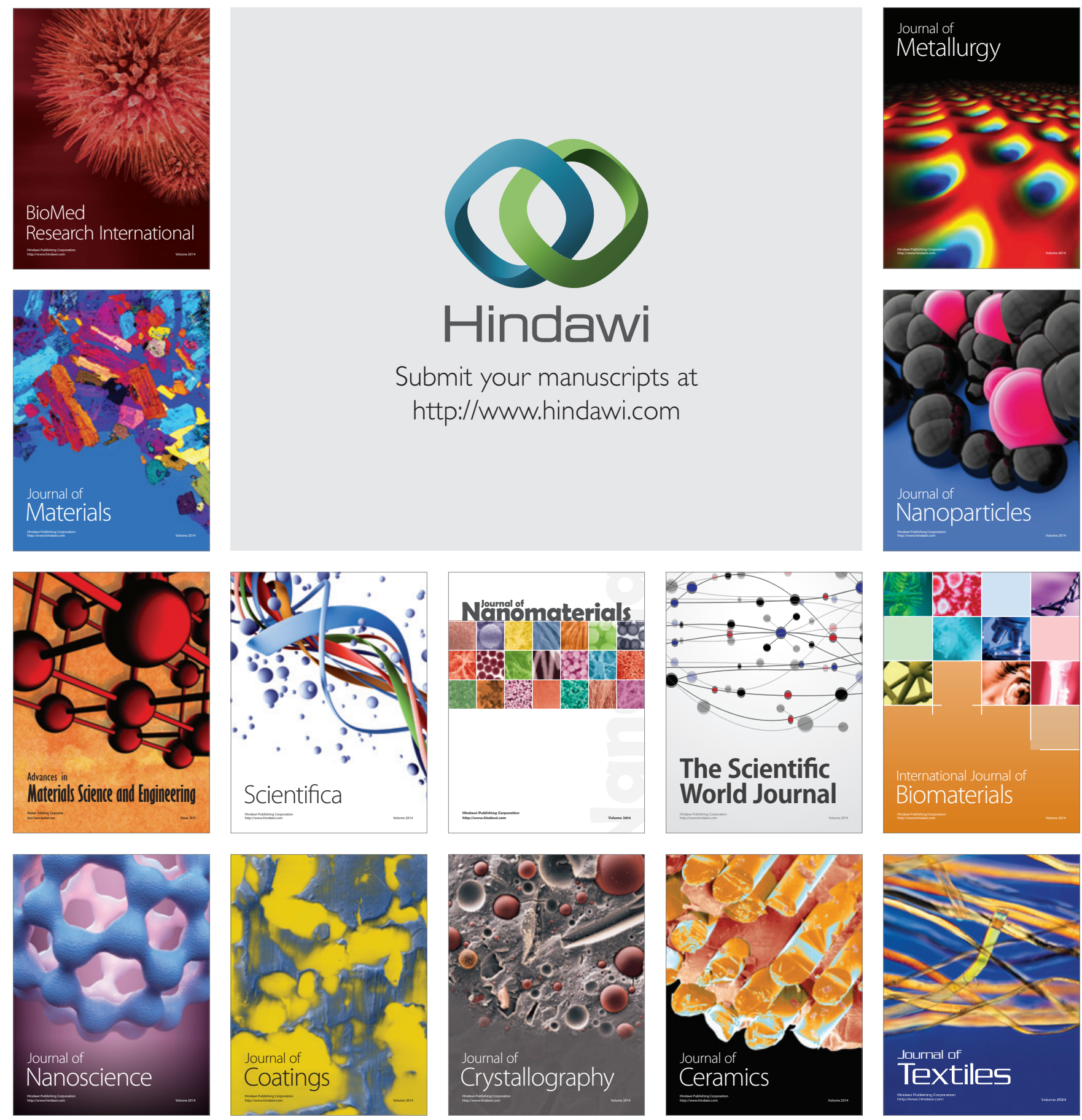